FEATURE

\title{
Reference Services to Incarcerated People, Part II Sources and Learning Outcomes
}

During the 2013/14 academic year, students taking a required general reference course in a library and information science program answered reference questions from incarcerated individuals. The assignment was designed as a servicelearning project. Here we examine how well the assignment met the course and program-level learning objectives that students are expected to attain. We described the data collection and analysis, present our findings and make recommendation in ways to increase student learning outcome and ALA professional competencies from a services learning projects. Specifically we discuss the need to increase education in e-government sources since our findings indicated they are most useful for answering reference questions from incarcerated people.

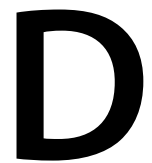

uring summer of 2013, a librarian from the New York Public Library (NYPL) department that services the city's correctional facilities posted a message to a New York, NY-area library listserv looking for volunteers to answer reference questions from incarcerated people. The authors, who teach a general reference course at a New York City (NYC) LIS school, contacted the supervising librarian of the New York Public Library's Correctional Services program and volunteered their students to the task.

This article describes the results of two semesters of work. In the first section we describe the theoretical justifications for taking on the project. These justifications stem from two frameworks, service learning and professional commitment. Next, we describe the procedures and method for the project and describe the data sources and collection methods as well as the limitations. This is followed by an analysis of the data and discussion of the findings. Finally, we will conclude with the project outcomes and make recommendations for further development of the project.

\section{LIBRARY SERVICES TO PEOPLE IN PRISON}

Library services to incarcerated people in New York City and New York State are provided under myriad laws, regulations, and services. Prisoners do not have online access and their access to information is generally limited. Prisons are required by federal regulation to provide incarcerated people with access to the courts that meet a threshold of "reasonable access" by either by establishing law libraries in correctional

\section{Debbie Rabina and Emily Drabinski}

Debbie Rabina (drabina@pratt .edu) is Professor at Pratt Institute, School of Library and Information Science in New York, New York. Emily Drabinski (emily.drabinski@liu .edu) is Coordinator of Instruction at Long Island University, Brooklyn, in Brooklyn, New York.

\section{We wish to thank Sarah Ball,} Supervising Librarian of the New York Public Library Correctional Services Program for her invaluable guidance and support throughout the project and Emily Jacobson, NYPL Correctional Services librarian. We also wish to thank the 38 participant students for their service and commitment.

Reference \& User Services Quarterly, vol. 55, no. 2, pp. 123-31

(c) 2015 American Library Association. All rights reserved.

Permission granted to reproduce for nonprofit, educational use. 


\section{FEATURE}

facilities or by assigning lawyers for inmates or inmates to sources. ${ }^{1}$ Given this state of affairs, inmates' ability to access information is limited and restricted in both print and online availability.

New York State provides limited library services to incarcerated people, focusing on law library services intended to help inmates aid in their own defense. ${ }^{2}$ NYPL provides services beyond those required by law under their community outreach program. ${ }^{3}$ NYPL Correctional Services delivers literacy programming to teens and adult inmates in the NYC area, Riker's Island, and other area correctional facilities, and provides mail reference services to inmates. Since NYPL's program offers unique services, not available in other jurisdictions, they often receive reference requests from other cities and states, and make every effort to meet all reference requests. Many of the reference questions are answered by volunteers who are supervised by the NYPL librarians.

As of March 2014, New York housed more than 80,000 incarcerated people in both county and state facilities. The NY State Department of Correctional Services houses people who have been sentenced for longer than one year. In March 2014 this number was 53,968 people. ${ }^{4}$ The remainder of incarcerated men and women are housed in county jails. The City of New York Department of Correction (DOC) has their own jurisdiction over the five boroughs and the people in prison there. Rikers Island is the main facility for New York City's DOC, with a capacity of housing approximately 15,000 individuals and a daily average of 12,000 . It is a ten-jail compound located in the East River adjacent to LaGuardia Airport. ${ }^{5}$

New York State provides library services to its incarcerated population at both the state and county levels, but that service varies depending on location and the number of people in each facility. At the state level, general libraries are required to follow NY State Commission of Correction standards. ${ }^{6}$ They are modeled on public libraries, staffed by librarians, and offer educational, informational, reference, and referral services to incarcerated patrons. As indicated above, prisons are required by federal regulation to provide incarcerated people with access to the courts that meet a threshold of "reasonable access" by either by establishing law libraries in correctional facilities or by assigning lawyers for inmates or inmates to sources. New York State has chosen to fulfill this requirement by establishing law libraries in State correctional facilities. ${ }^{7}$ Of the ninety prison law libraries in the state of New York, only four are staffed by librarians, the rest are staffed by correctional officers. County jails are different from state correctional facilities in that there is no state statutory that mandates general library services, however, legal resources are mandated through NY State's Commission of Correction. The New York State Library (NYSL) provides financial services to the state and county correctional facilities and helps maintain collections and resources for patrons. General libraries receive funding from NYSL based on incarceration populations: state correctional facilities receive $\$ 9.25$ annually per incarcerated person and county facilities receive a flat $\$ 175,000 .{ }^{8}$

The New York Public Library is one of the large public libraries to take an active role in providing library services to incarcerated individuals. In addition to the city and state mandated services, the Correctional Services Program at NYPL also delivers literacy programming to teens and adults in the justice system, circulates library services inside jail facilities, and provides mail reference services both within and beyond New York State. The most recent statistics from NYPL estimate more than nine hundred unique interactions are provided each month in the New York City area and that services reached twelve New York State facilities in December of 2012. ${ }^{9}$ This does not include the large number of reference letters that Correctional Services receives, many of which are answered by volunteers under NYPL supervision. NYPL typically receives eight to fifteen reference requests from inmates weekly. These can range from the straightforward (e.g., list of halfway houses in the Syracuse area) to the intricate (e.g., detailed requests on starting a business, historical information, medical information, etc.). Many of the questions regarding inmate re-entry into society upon release are answered by publications prepared by NYPL. Questions on all other topics are answered by volunteers who conduct necessary research and data collection to compose the responses.

\section{PROJECT GOALS AND RATIONALE}

This project was designed to achieve outcomes that are consistent with the objectives of teaching students to provide information services and sources. These objectives are defined by the American Library Association (ALA) as part of their core competencies ${ }^{10}$ and are reflected in the course description. Both the ALA competencies and the course objectives emphasize selection and evaluation of sources (ALA competency 5B), interaction with users (ALA competency 5C), and response to user needs (ALA competency 5F). In addition, the project was designed to meet program-wide objectives pertaining to research, communication, user-centered focus and LIS practice. ${ }^{11}$

We considered this project as particularly suitable for imparting reference skills and reinforcing professional ethical practices since it addresses actual information needs of real people, rather than the more typical instructor-generated reference questions. The pedagogy employed here is one of service learning, also referred to as experiential learning. John Dewey identified experiential learning as necessary for fostering learning in his book Experience and Education, an approach that has been widely used in library and information science education, most recently by Brzozowski, Homenda, and Roy; Currim, Cocciolo; Cooper; Overall; and Riddle. ${ }^{12}$

Brzozowski, Homenda, and Roy (2012) and Currim (2011) are recent examples of the use of service learning for LIS students as a way to directly introduce them to reference services 
and public library services. Currim describes how answering real users' reference questions helps students develop reference skills while providing a public service. Through answering reference questions on a non-for-profit website, specifically Internet Public Library2 (IPL2.org) students develop better people skills and achieve deeper levels of learning that reinforce the ALA core competencies. ${ }^{13}$ Similarly, a group of researchers who instructed LIS students in a service learning project at a large urban public library found that service learning helps bridge the divide between theory and practice, helps students better understand the community they are serving, and allows students to grow personally and professionally. ${ }^{14}$

\section{PROBLEM STATEMENT AND RESEARCH QUESTIONS}

From the theoretical framework that guides our approach to service learning, we developed the following research questions aimed at identifying how well this project met the learning objectives at the course and program level.

RQ1: What types of sources are used most often when responding to inmates' reference requests?

RQ2: What student learning objectives are reinforced by this project?

\section{METHOD}

\section{Basic Procedure}

Students enrolled in an introductory reference course at Pratt Institute, School of Information and Library Science in NYC participated in the program during the Fall 2013 and Spring 2014 semesters. This is a required course, taught in a face-to-face classroom over the course of 15 weeks. A total of thirty-eight students participated in the project in two consecutive sections of the course.

On the second week of each semester, a representative from NYPL came to the class to describe the reference services provided by mail to incarcerated people, the proper protocol for the answers including NYPL practices and protocol for protecting patron confidentiality, the standard format and disclaimers accompanying each letter, length limitation set by the correctional facilities on inmates' mail, and, finally, the reference sources available from NYPL specifically for incarcerated patrons. One of these sources is Connections: a 268-page guide of resources to assist people in prison with reentry into society. The library distributes this guide to patrons often, and it is always in high demand (the 9000 copies print for 2014 ran out by mid-September).

Following the orientation session, we received on a weekly basis scanned letters from NYPL Correctional Services and the instructor assigned them to students. This occurred in the beginning of class and each letter was read out loud and was followed by a discussion of the best search strategies and sources for filling the information request. Each student answered three inmate letters. The instructor made efforts for each student to answer questions addressing different subject areas.

Students had four to five days to respond to the question. Answers were emailed to the instructor, who reviewed the answers, and if necessary, requested corrections or modifications. Once complete, the answers were emailed to NYPL where they were printed out and mailed to the patrons. The process of answering the questions, including time needed for modifications, was one week.

\section{Data Sources}

The results presented here are based on two data sources. The first data source is a set of 112 letters written in response to inmates' reference questions. The second data source were thirty-eight post-project reflections that were collected from students. Student reflections were analyzed to identify the learning outcomes achieved by the project and for evidence linking the outcomes to program-wide student learning objectives, course objectives, and increased professional responsibility.

\section{Data Analysis}

The researchers completed Human Subject Assurance training as required by their university and followed patron confidentiality guidelines practiced by New York Public Library. All identifying information was separated from the reference questions, and no personal information was collected.

The researchers employed mainly qualitative content analysis methods and applied them to issues and themes that emerged from the data sources. Analysis followed steps described by Zhang and Wildmuth and included data preparation (anonymizing questions and responses, collecting data sources into spreadsheet), defining the unit of analysis (inmates questions, students responses, student reflections), developing themed categories, and coding the data sources. ${ }^{15}$

Manual coding was carried out the by the authors who identified broad categories based on the research questions. Both authors coded a sample of the data sources (8 percent) to determine inter-rater reliability, which was achieved at a 90 percent level. Subsequently, coding of data sources was divided between the authors.

\section{Research Limitations and Project Challenges}

This study is exploratory in nature and is the first in a series of research projects to come. To best allow themes to emerge, we did not prescribe a vocabulary or offer instructions to students beyond those necessary to the project. In other words, rather than ask students to indicate which of the course objectives were met in this project, we asked more open-ended questions such as "what did you learn from this project." 


\section{FEATURE}

Table 1. Summary of reference materials used, absolute numbers

Type of Source Used

Government sources:

federal, state, and local

Traditional reference sources:

bibliographies, directories,

encyclopedias, newspaper,

and article databases

\section{Miscellaneous websites: \\ commercial and user \\ generated}

Connections book

Open access reference/scholarly sources

Advocacy groups

\section{No. Examples of Sources}

70 New York City Housing Authority (NYCHA)

Small Business Administration

FAFSA

58 Oxford Companion to the Earth

Wikipedia

Britannica

Literary Market Place

ScienceDirect

40 J.K. Rowling fan club

About.com

Publishers' websites

25 NYPL publication for NY inmate population

18 Pubmed

National Geographic maps

14 Legal Aid Society

NACCP legal defense fund
While this made coding more challenging, we preferred not to limit students' reporting in the narrow vocabulary of the syllabus. Since this project is ongoing, the theme and categories that emerged from coding students' narratives will inform our future research projects.

We also faced challenges directly relating to the project, rather than to the data analysis. There were some questions we received that were outside the scope of allowed responses. NYPL does not answer any requests for private information, such as personal addresses or phone numbers. In cases when such requests were received, if a public address was available it was sent with an explanation that private information is outside scope. In another case, a patron asked for information about a group responsible for prison uprisings in Latin America, and this information was deemed too controversial to provide [S14_R_17]. In another case, the information provider (the Church of Satan) refused to respond to a student's request because the information would be shared with someone in prison [S14_R_07]. These limits on allowable content were unique to the population served.

\section{RESULTS}

As mentioned above, this project was part of a course in general reference, titled Information Services and Sources. The course focuses equally on introducing students to a variety of reference materials, as well as the service processes required for providing effective answers to reference questions. These two main objectives are articulated in the course description, as follows:

The course introduces the selection and evaluation of resources in all formats, the development of searching techniques, strategies for user-centered service, matching user needs to resources, and the provision of information services in changing technological environments.

To examine whether students used a variety of reference materials, we asked the following research question:

RQ1:What types of sources are used most often when responding to inmates' reference requests?

Table 1 shows the types of reference materials used by students. We identified six unique groups of reference types:

1. Government sources: This group included information sources from federal, state, and local information sources. These are all official websites with the extension gov.

2. Traditional reference sources: These include bibliographic, biographic, geographic sources, directories, dictionaries, encyclopedias, and article databases. These have long been the bread-and-butter of reference instruction and still dominate the reference textbooks. While many of these are proprietary, we did include in this category freely available sources such as Wikipedia.

3. Miscellaneous websites and user-generated content: This category includes both commercial and usergenerated content such as websites of car manufacturers, book publishers, and similar. Hobbyist websites used included sites devoted to song lyrics or baseball statistics.

4. Connections: This category included questions that were answered using the NYPL Connections book that provides incarcerated people with information to prepare them for reentry into society upon their release.

5. Open access sources: In this group we included sources that are freely available to the public but are more scholarly in nature than those included in the 


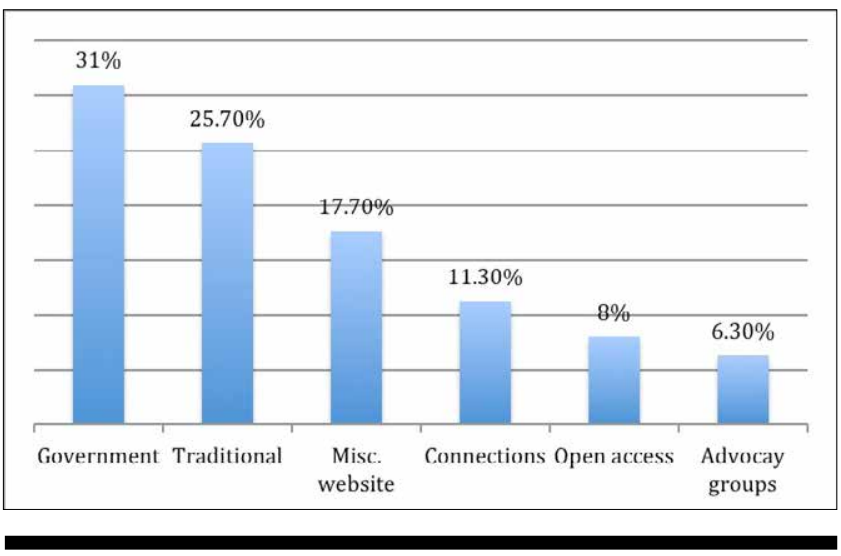

Figure 1. Types of reference materials used, percent

miscellaneous websites category. For example, students discovered that a good way to answer a very broad question was to provide a course syllabus on the topic. One inmate wanted information about "neuroscience." The student answered the question by sending a syllabus for an introductory university course and suggesting to the inmate that they write back with more specific questions.

6. Advocacy groups: These include non-government agencies that work directly or indirectly with inmates, such as various legal aid groups, groups focusing on educational, emotional, or social support of inmates and their families.

We found that the most frequently used sources were government sources, followed by traditional reference sources. The complete numeric breakdown, including examples of each type, is available in table 1.

Figure 1 shows the breakdown of the types of materials used as percentages. The largest groups, government information, accounted for 31 percent of the sources used, with advocacy groups providing the smallest percentage, 6.3 percent.

Since government sources emerged as a leading type, we wanted to learn more about the government sources used and to distinguish in a more granular way the types of sources that were used to respond to reference questions. We divided all government sources into groups by level of government: Federal, state, and local government, as well as international, which included foreign governments and non-governmental organizations (NGO). Table 2 shows the types of government sources used.

As instructors, it was our responsibility to assure that each student utilized a range of reference sources. To guarantee to the extent possible that each student will use different types of reference materials, we assigned each student letters that covered different areas. Upon examining the types of materials used by each student individually, we found that on average, each student used 3.5 reference types (i.e., not unique sources, but sources belonging to different group types), with a mode of 4 . This analysis, displayed in figure 2 , included only the reference types ultimately used for the answer, and not all the sources used during the various stages of the search process.

\section{Learning Objectives}

Finally, we wanted to know whether this form of service learning was successful in helping students achieve program-level and course-level objectives, as expressed in our second research question:

RQ2: What student learning objectives are reinforced by this project?

We derived the course-level objectives from the course syllabus and grouped them into three categories that reflect both course-level objectives and the ALA core competencies 5B, 5C and 5F for Reference and User Services (see endnote 10):

- Selection and evaluation: Ability to understand and evaluate information sources, services, and activities in a variety of applied contexts

- Human interaction: Knowledge of the process of learning from a variety of sources and in different settings and ability to manage that process

- Professional ethics: Ability to make professional and socially responsible decisions in managing the process through which information agencies and organizations provide access to information to individual users and different groups of users

To answer this question, we asked students to provide detailed reports of their experience within one week of completing the final letter response.

Upon coding the reports we found that the percentage of students who reported that these course-level objectives were met ranged between 50-58 percent. Figure 3 shows course objectives met.

In addition, in RQ2 we wanted to capture the extent that this project met the program-level learning objectives. We defined program level objectives as those competencies students must demonstrate as a graduation requirement, specifically:

1. Research-Students carry out and apply research

2. Communication-Students demonstrate excellent communication skills and create and convey content

3. Technology-Students use information technology and digital tools effectively

4. User-Centered Focus-Students apply concepts related to use and users of information and user needs and perspectives

5. LIS Practice-Students perform within the framework of professional practice 


\section{FEATURE}

Table 2. Summary of reference materials used, absolute numbers

\section{Type of Source Used}

Federal government

State government

Local government

International and NGO

\section{No. Examples of Sources}

29 US Patents and Trademark Office

Small Business Administration

Bureau of Alcohol, Tobacco and Firearms

Centers for Disease Control and Prevention

17 NYS Dept. of Homeless Services

NY Dept. of State

NYS Dept. of Environmental Conservation

NYS Dept. of Labor

21 NYC dept. of Sanitation

NYC Housing Authority

MTA

3 Gov. of China

United Nations
Most students, 79 percent, felt that the assignment met the program-level outcome of research, and 63 percent felt they satisfied the objective of user-centered focus. Figure 4 shows the extent to which each of the program-level outcomes were met.

\section{Sources Used by Students}

We wanted to learn more about the different types of reference sources used by students while answering inmates' questions. While we appreciated the social value of the assignment, as instructors we wanted to know if this assignment met the objective of a general reference course that introduces students to a range of materials. We discovered that students used a wide variety reference sources to answer the question, thus fulfilling the course-level objective:

Knowledge of a variety of information sources: how they are structured, how information is retrieved from them, and about the contexts in which these resources function to communicate information (taken from course syllabus)

Students used mostly open access sources, but some proprietary article databases available from NYPL were used as well (ScienceDirect, Gale). They used PubMed and, directories and encyclopedias, and many newspaper archives from NYPL databases. By far the most surprising finding was that the largest resource group, almost a third (31 percent), was government information sources. These included the USPTO (US Patents and Trademark Office), FDsys Federal Digital System), and many more. One student said:

In answering these questions, government websites proved to be the most useful and inclusive source [F13_R_05]

Another student appreciated the intricate knowledge required to gain expertise in government information:

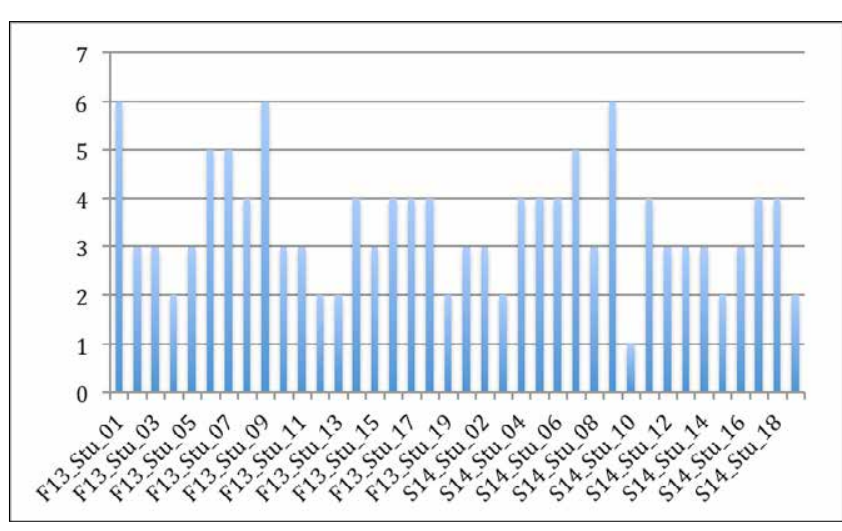

Figure 2. Number of reference types used by each student

The request for information about trademarking a name for a product line, and for starting new lines of clothing or soap required investigation into the United States Trademark and Patent Office website, looking for both product codes and procedural information. This required exploring the internal vocabulary used within the Trademark database, which was more complex and specific than expected. [F13_R_06]

This was supported by another statement in a report:

My initial thought was to include the official text of the law from US Code. However, given its length and dense legal language, I opted to instead include articles addressing the issue of ADA compliance for prisoners. This included a memo from the New York Department of State, and articles published online from advocacy organizations serving the disabled and prisoners. [F13_R_12]

LIS students interested in government information sources usually take a specialized reference course in this area. Such courses tend to focus heavily on statistical and 


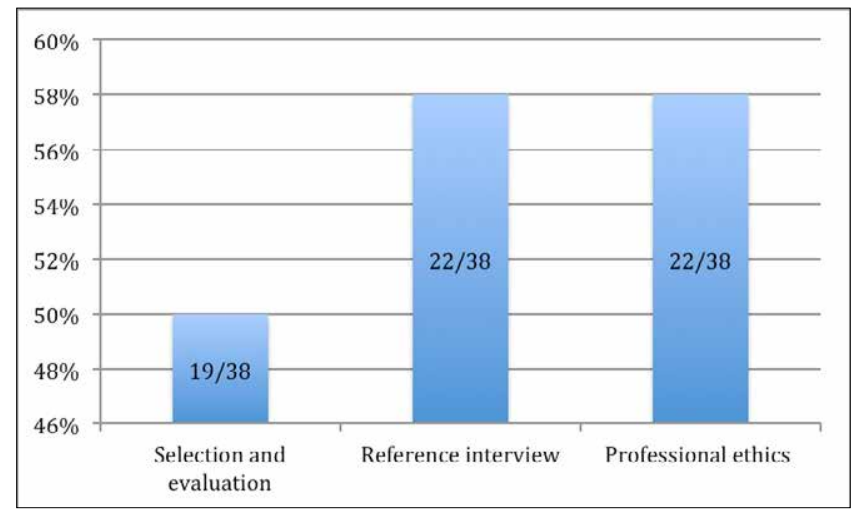

Figure 3. Course learning outcome met

legislative information sources and are designed to assist advanced users in academic and research libraries. Introductory reference sources touch upon government sources in a cursory way and they are considered outside the scope of general reference. However, in recent years researchers have been arguing that government sources play an important role for public librarians in providing free access to public information. ${ }^{17}$

Given our evidence of the role of government sources in answering reference questions, we make our first recommendation:

Recommendation 1: Increase the teaching of government information sources to all students taking a required reference course.

\section{Service Learning Perspective}

We designed this project first and foremost to support the learning objectives of the students. These included outcomes pertaining to reference sources and selection, as discussed above, and outcomes pertaining to professional ethics, discussed below.

The majority of the students, 58 percent, indicated in their project reports that this project imparted lessons in professional ethics and human interactions. While this number is not as high as we would like, we hypothesize that this number can be accounted for by the fact that the report instructions were broadly phrased and did not solicit responses to specific objectives. In addition, a higher percentage of students, 63 percent, indicated that they developed a user-centered approach as a result of this project.

From this we draw our second recommendation:

Recommendation 2: Provide more detailed questions for students to address in the project reports.

Nonetheless, the majority of students did benefit directly in the area of professional ethics. One student expressed her growing understanding of her role:

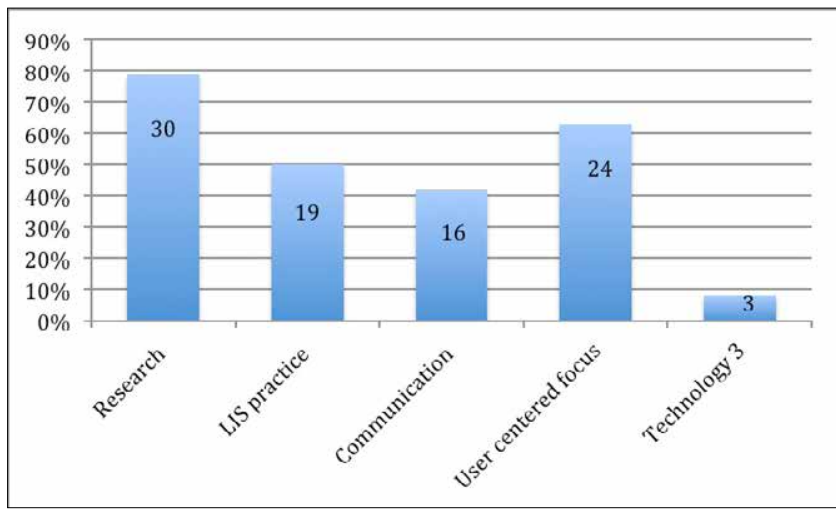

Figure 4. Program level outcomes achieved

In a sense, I felt like an information liaison to the informationally challenged. [F13_R_04]

Students took pride in having participated in the project:

[it] was a unique and valuable opportunity for us to provide reference services to individuals whose access to information was limited. [F13_R_12]

It is a very special privilege to be allowed to help people in this situation. Most of us take access to the [I]nternet for granted and providing a service to those without forces one to consider their circumstances and imagine life from their perspective. [F13_R_15]

Because of my personal politics, I was very excited to participate in this project even before the class began. I feel that access to information is a fundamental human right, and I also believe in the humanization and assistance to people who are incarcerated, as a form of prison abolition work. So, I greatly enjoyed having a portion of class that also had a real-world impact on people's lives. [SP14_R_04]

Students also considered the guidelines from NYPL about information that is out of scope. The out-of-scope designation includes information about individuals-personal information such as address and phone number. There were several requests for personal information, but only information that is publicly available, such as professional contact information, was provided.

A student commented on this by saying:

This letter was very interesting since it made me question whether giving him this information was okay since he may have known the person personally, but since it was public knowledge my concerns were assuaged. [F13_R_08] 


\section{FEATURE}

Accordingly, students drew some important lessons on the reserving of judgment:

Another thing that I learned from the assignment was how to conduct reference in a professional and socially responsible manner. Lastly, I had to make sure my responses were neutral, adequate and not influenced by my preconceived notions of inmates or other particular situations. [F13_R_11]

I was forced to set aside my prejudices and anger toward these criminals and attempt to provide them with the best reference services I could provide in letter form. It is not my place to judge anyone. [SP14_R_14]

The second half of the question about crystals and minerals presented me with a conundrum. I believe that the use of crystals for healing is pseudoscience, but felt that the inmate had expressed an information need and it was my job to fulfill it without judgment [F13_R_01]

Students learned to overcome challenges arising from poor handwriting, poor language, or lengthy requests. One student observed:

My third letter had a rather lengthy but specific list of requested information. The inmate requested the names of ambassadors from seven countries to the United States, as well as postal and email addresses for their embassies in Washington, DC. He also requested the name of Permanent Representatives to the United Nations from three countries and the postal and email addresses for their Missions in New York. Finally, he requested postal and email addresses for seven major newspapers in the United States. [F13_R_12]

Another limitation is on certain supervised materials, although they are not defined anywhere. One student came across the following problem:

I originally was worried that I would not be able to answer this question. Loompanics, Delta Press, and Paladin Press all publish material that would not be allowed to enter a prison: books on guns, self defense, and martial arts. Delta Press publishes the infamous Anarchist Cookbook, which contains instructions for making bombs and manufacturing drugs at home. With instructions from Sarah Ball, Supervising Librarian of the NYPL's Correctional Services program, I sent samples from the catalogs, hoping they would get through prison security because they do not actually contain any of the objectionable content. [F13_R_02]
Perhaps best indicative of the overall fulfillment of learning objectives came from the following student statement:

This task was not only extremely valuable from a learning perspective, but also personally rewarding. This was a unique and highly effective way to respond to real-world reference requests, while at the same time providing an invaluable service to members of society with limited access to information. I was able to apply skills learned in the classroom to the practical task of providing relevant information to satisfy the request of someone in need. In the process I was able to hone my own reference and research skills, utilizing sources and search strategies from my own experience and learned in the classroom. I was also able to apply my own communication skills in drafting the written responses-seeking professionalism at each step of the way. Ultimately this task made me more confident in my reference abilities and I appreciated the rewarding opportunity to provide assistance to someone with a need. [F13_R_12]

\section{CONCLUSIONS AND FURTHER RESEARCH}

From a service-learning perspective, this project was successful in meeting the course and program learning objectives while providing a rewarding experience for students. The results of our study established that we were able to fulfill the learning objectives of students as well as to provide valuable reference services to our users.

This project demonstrates the vital role of government information in serving the needs of incarcerated individuals and in increasing student learning outcomes. In addition to serving the needs of people in prison, government information proved valuable as a knowledge platform for student engagement.

We intend to continue this service to incarcerated individuals in a joint effort with NYPL, and to expand the research in this area. We are in the process of collecting direct feedback from prison patrons by including a set of satisfaction questions for them.

\section{References}

1. 28 CFR 542.1-Purpose and Scope, www.law.cornell.edu/cfr/ text/28/543.10.

2. "Library Services in New York State's Correctional Facilities," New York State Library, www.nysl.nysed.gov/libdev/outreach/ corr.htm.

3. "Correctional Services Program," www.nypl.org/help/commu nity-outreach/correctional-services.

4. "Inmate Population Statistics," New York State Commission of Correction, April 5, 2014, www.scoc.ny.gov/pop.htm

5. "About DOC: Facilities Overview," City of New York Department of Correction, 2014, www.nyc.gov/html/doc/html/about/facilities_overview.shtml. 
6. "Library Services in New York State's Correctional Facilities," New York State Library, accessed October 14, 2008, www.nysl .nysed.gov/libdev/outreach/corr.htm.

7. Ibid

8. Ibid.

9. "Correctional Services Program: Correctional Services Monthly Statistics," New York Public Library, 2014, www.nypl.org/help/ community-outreach/correctional-services/stats.

10. "ALA's Core Competences of Librarianship, Reference and User Services," American Library Association, January 29, 2009, www.ala.org/educationcareers/sites/ala.org.educationcareers/files/content/careers/corecomp/corecompetences/finalcore compstat09.pdf; Pratt course catalog, https://www.pratt.edu/ academics/degrees/course-catalog.

11. Pratt e-portfolio, https://www.pratt.edu/academics/information/ about-the-school/student-learning-outcomes.

12. John Dewey, Experience and Education (New York: Simon \& Schuster, 1997); Bonnie Brzozowski, Nicholas Homenda, and Loriene Roy, "The Value of Service Learning Projects in Preparing LIS Students for Public Services Careers in Public Libraries," Reference Librarian 53 (2012): 24-40; Sarah Currim, "Experiential Learning: Reducing the Real-World Divide between Libraries and Library School," Reference Librarian 52 (2011): 300-307; Anthony Cocciolo, "Public Libraries and PBS Partnering to
Enhance Civic Engagement: A Study of a Nationwide Initiative," Public Library Quarterly 32, no. 1 (2013): 1-20; Linda Z. Cooper, "Student Reflections on an LIS Internship from a Service Learning Perspective Supporting Multiple Learning Theories," Journal of Education for Library E Information Science 54, no. 4 (2013): 286-98; Patricia Montiel Overall, "The Effect of Service Learning on LIS Students' Understanding of Diversity Issues Related to Equity of Access," Journal of Education for Library and Information Science 51, no. 4 (2010): 251-66; John Riddle, "Information and Service Learning," in Critical Library Instruction: Theories and Methods (Duluth, MN: Library Juice Press, 2010), 133-48.

13. Currim, Experiential Learning, 300-307.

14. Brzozowski et al., The Value of Service Learning Projects, 24-40.

15. Yan Zhang and Barbara Wildemith, "Qualitative Analysis of Content," in Applications of Social Research Methods to Questions in Information and Library Science (Westport, CT: Libraries Unlimited, 2009), 308-19.

16. "Corrections Statistical Analysis Tool (CSAT)_Prisoners," Bureau of Justice Statistics, www.bjs.gov/index.cfm?ty=nps.

17. Paul T. Jaeger and John Carlo Bertot, "Responsibility Rolls Down: Public Libraries and the Social and Policy Obligations of Ensuring Access to E-government and Government Information," Public Library Quarterly 30, no. 2 (2011): 91-116, http:// dx.doi.org/10.1080/01616846.2011.575699. 